\title{
Medical Multimorbidity, Mental Illness, and Substance Use Disorder among Middle-Aged and Older Justice-Involved Adults in the USA, 2015-2018
}

\author{
Benjamin H. Han, $\mathrm{MD}^{\top}$ (D) , Brie A. Williams, MD², and Joseph J. Palamar, PhD $^{3,4}$ \\ 'Department of Medicine, Division of Geriatrics and Gerontology, University of California San Diego, 9500 Gilman Drive, Mail Code 0665, San Diego, \\ CA, USA; ${ }^{2}$ Department of Medicine, Division of Geriatrics, University of California San Francisco, 3333 California Street, San Francisco, CA, USA; \\ ${ }^{3}$ Department of Population Health, New York University Grossman School of Medicine, 550 First Avenue, New York, NY, USA; ${ }^{4}$ Center for Drug Use \\ and HIV/HCV Research, NYU School of Global Public Health, 665 Broadway, New York, NY, USA.
}

\begin{abstract}
BACKGROUND: Adults age $\geq 50$ are among the fastest growing populations in correctional supervision and are medically underserved while experiencing unique health disparities. Community-living older adults, referred to as "justice-involved," are people who have been recently arrested, or are on probation or parole. Although medical complexity is common among incarcerated older adults, the occurrence of medical morbidity, substance use disorder (SUD), and mental illness among justice-involved older adults living in US communities is poorly understood.
\end{abstract}

OBJECTIVE: To estimate the prevalence of medical multimorbidity ( $\geq 2$ chronic medical diseases), SUDs, and mental illness among justice-involved adults age $\geq$ 50 , and the co-occurrence of these conditions.

DESIGN: Cross-sectional analysis.

PARTICIPANTS: A total of 34,898 adults age $\geq 50$ from the 2015 to 2018 administrations of the US National Survey on Drug Use and Health.

MAIN MEASURES: Demographic characteristics of justice-involved adults age $\geq 50$ were compared with those not justice-involved. We estimated prevalence of mental illness, chronic medical diseases, and SUD among adults age $\geq 50$ reporting past-year criminal justice system involvement. Logistic regression was used to estimate the odds of these conditions and co-occurrence of conditions, comparing justice-involved to non-justice-involved adults.

KEY RESULTS: An estimated 1.2\% (95\% confidence interval $[\mathrm{CI}]=1.1-1.3$ ) of adults age $\geq 50$ experienced criminal justice involvement in the past year. Compared with non-justice-involved adults, justice-involved adults were at increased odds for mental illness (adjusted odds ratio $[\mathrm{aOR}]=3.04,95 \% \mathrm{CI}=2.09-4.41)$ and $\mathrm{SUD}(\mathrm{aOR}=8.10$, $95 \% \mathrm{CI}=6.12-10.73)$, but not medical multimorbidity ( $\mathrm{aOR}=1.15,95 \% \mathrm{CI}=0.85-1.56)$. Justice-involved adults were also at increased odds for all combinations of the three outcomes, including having all three simultaneously $(\mathrm{aOR}=8.56,95 \% \mathrm{CI}=4.10-17.86)$.

Electronic supplementary material The online version of this article (https://doi.org/10.1007/s11606-020-06297-w) contains supplementary material, which is available to authorized users.

Received May 15, 2020

Accepted October 5, 2020

Published online October 13, 2020
CONCLUSIONS: Community-based middle-aged and older adults involved in the criminal justice system are at high risk for experiencing co-occurring medical multimorbidity, mental illness, and SUD. Interventions that address all three social and medical risk factors are needed for this population.

KEY WORDS: justice-involved; older adults; multimorbidity; substance use.

$\mathrm{J}$ Gen Intern Med 36(5):1258-63

DOI: $10.1007 / \mathrm{s} 11606-020-06297-\mathrm{w}$

(c) Society of General Internal Medicine 2020

\section{INTRODUCTION}

The number of incarcerated older adults is increasing in the United States (US), as the population of adults age $\geq 55$ in prisons increased $280 \%$ from 1999 to 2016. ${ }^{1}$ Incarcerated adults have high rates of HIV/AIDS, cirrhosis, cardiovascular disease, ${ }^{2-4}$ mental illness, ${ }^{5}$ and substance use disorders (SUDs). ${ }^{6}$ The population of community-dwelling older adults who are involved in the criminal justice system ("justiceinvolved adults" - those recently arrested, on probation, or parole) is also growing. Middle-aged and older justiceinvolved adults are at high risk for these same chronic conditions, ${ }^{7}$ and are more likely to experience a higher burden of medical multimorbidity ( $\geq 2$ chronic medical diseases) and geriatric conditions. ${ }^{8}$ Yet the amount of intersection of chronic disease alongside mental illness and SUDs in older justiceinvolved adults is unknown.

Most studies about co-occurring conditions in the US prison population focuses on mental illness and SUDs among younger adults. ${ }^{6,9,10}$ However, medical multimorbidity, mental illness, and SUDs are all frequently interrelated and place individuals at risk for adverse outcomes. In general, older adults with multiple conditions have high rates of healthcare utilization and receive poorly coordinated care. ${ }^{11,12}$ Therefore, older justice-involved adults, many of whom have a history of poor access to healthcare and social services, are even less likely to receive coordinated care that addresses cooccurring conditions. This is particularly important for adults 
who are returning to the community from correctional institutions, ${ }^{13}$ a period that represents high susceptibility to healthrelated mortality. ${ }^{14,15}$

Few studies have estimated the prevalence of medical multimorbidity, mental illness, and SUDs among older justice-involved adults, ${ }^{7}$ and none have examined their cooccurrence. Therefore, this study aims to use nationally representative data to describe the health of middle-aged and older justice-involved adults through a multimorbidity framework to inform the development of multidisciplinary interventions.

\section{METHODS}

\section{Data Source and Study Population}

We performed data analysis on the 2015 through 2018 administrations of the National Survey on Drug Use and Health (NSDUH). NSDUH is a nationally representative annual cross-sectional survey of non-institutionalized, communityliving individuals in the USA. ${ }^{16}$ Surveys are administered via computer-assisted interviewing conducted by an interviewer and audio computer-assisted self-interviewing. Sample weights are provided by NSDUH to account for the complex survey design, non-response, selection probability, and population distribution. We limited analysis to individuals age $\geq 50$ $(n=34,898)$.

\section{Justice-Involved Status}

Participants were asked three questions regarding whether in the past year they were (1) arrested and booked for an offense, (2) on probation, or (3) on parole (or supervised release) in the past year. Similar to other studies, ${ }^{17,}{ }^{18}$ we coded these variables into a binary variable indicating any criminal justice involvement in the past year.

\section{Covariates}

We considered the following demographic characteristics: age (50-64 years of age and 65 years of age and older), gender, race/ethnicity, education, annual family income, relationship status, and by whether or not the participant reported having health insurance.

\section{Outcomes}

Mental Illness. NSDUH includes an indicator for past-year mental illness developed and validated by the Substance Abuse and Mental Health Services Administration and National Institute of Mental Health, which is based on responses to specific questions. ${ }^{19}$ The items include level of depression, emotional distress, functional impairment, and suicidal thoughts. The responses from each individual are coded into a variable indicating mild, moderate, and severe mental illness. Our definition for mental illness was limited to moderate or severe mental illness, equivalent to a Global Assessment of Functioning (GAF) score of $<60 .{ }^{19}$
Medical Multimorbidity. Participants were asked if they have been told by a doctor that they have asthma, chronic obstructive pulmonary disease (COPD), cancer, cirrhosis, diabetes, a heart condition, hepatitis $\mathrm{B}$ or $\mathrm{C}$, high blood pressure, HIV/AIDS, or kidney disease. We also coded a variable indicating whether participants reported being diagnosed with $\geq 2$ conditions to indicate medical multimorbidity. ${ }^{11}$

Substance Use Disorder. Participants reporting past-year use of psychoactive substances were asked to answer DSM-IV questions about potential "abuse" and "dependence." Similar to other studies, ${ }^{20,}{ }^{21}$ while NSDUH is not a diagnostic interview, we considered the proxy diagnoses of either as pastyear SUD. The specific substances queried included use of alcohol, cannabis, cocaine, heroin, methamphetamine, and prescription opioids, stimulants, and tranquilizers or sedatives, with the latter two categories including benzodiazepines, muscle relaxants, zolpidem, eszopiclone, zaleplon products, and barbiturates.

Analysis. We estimated the prevalence of criminal justice involvement and compared whether there were differences in criminal justice involvement based on demographics, mental illness, medical multimorbidity, and SUDs. Bivariable comparisons were conducted using Rao-Scott chi-square ${ }^{22}$ to determine differences for each of these conditions with respect to past-year justice involvement. Next, using separate multivariable models which used forced entry of covariates, we determined whether criminal justice involvement was associated with each outcome, and with co-occurrence of outcomes. This resulted in 16 separate multivariable models which controlled for demographic characteristics (age, gender, race/ethnicity, marital status, education, income, and health insurance). To account for potential family-wise error resulting from multiple models, we used a Bonferroni statistical correction ( $\alpha=0.003 ; 0.05 / 16$ separate outcomes) to determine significance. We also ensured that multicollinearity was not present. Weights were included in all analyses and Stata 13 SE was used to analyze all data and we used Taylor series estimation to provide accurate standard errors. ${ }^{23} \mathrm{Sec}-$ ondary analysis of this publicly available data was exempt for review by New York University's Institutional Review Board.

\section{RESULTS}

An estimated $1.2 \%$ (95\% confidence interval $[\mathrm{CI}]=1.1-1.3$ ) of adults in the US age $\geq 50$ experienced criminal justice involvement. Table 1 presents demographic characteristics according to criminal justice involvement. Those who were younger, male, Black, not married, not having health insurance, those reporting lower educational attainment, and lower family annual income were more likely to report criminal justice involvement (all $p$ s $<0.001$ ). 
Table 1 Demographic Characteristics of Middle-Aged and Older Adults According to Justice-Involved Status in the USA, 2015 -2018

\begin{tabular}{|c|c|c|c|c|c|c|}
\hline \multirow[t]{2}{*}{ Characteristic } & \multicolumn{2}{|c|}{$\begin{array}{l}\text { Full population age } 50 \text { and } \\
\text { older }(n=34,898) \text { weighted } \% \\
(95 \% \mathrm{CI})\end{array}$} & \multicolumn{2}{|c|}{$\begin{array}{l}\text { Non-justice-involved adults age } \\
50 \text { and older }(n=34,437), \\
\text { weighted } \%(95 \% \text { CI })\end{array}$} & \multicolumn{2}{|c|}{$\begin{array}{l}\text { Justice-involved adults age } 50 \\
\text { and older }(n=461) \text {, weighted } \\
\%(95 \% \text { CI })\end{array}$} \\
\hline & Weighted \% & $95 \% \mathrm{CI}$ & Weighted \% & $95 \% \mathrm{CI}$ & Weighted \% & $95 \% \mathrm{CI}$ \\
\hline \multicolumn{7}{|c|}{ Justice-involved categories (past-year) } \\
\hline Arrested and booked & 0.8 & $(0.7-0.9)$ & $\mathrm{n} / \mathrm{a}$ & $\mathrm{n} / \mathrm{a}$ & 67.3 & $(61.5-72.6)$ \\
\hline Probation & 0.6 & $(0.5-0.7)$ & $\mathrm{n} / \mathrm{a}$ & $\mathrm{n} / \mathrm{a}$ & 47.6 & $(41.8-53.4)$ \\
\hline Parole & 0.2 & $(0.2-0.3)$ & $\mathrm{n} / \mathrm{a}$ & $\mathrm{n} / \mathrm{a}$ & 20.9 & $(16.3-26.5)$ \\
\hline \multicolumn{7}{|l|}{ Age } \\
\hline $50-64$, years & 55.9 & $(55.2-56.6)$ & 55.5 & $(54.8-56.2)$ & 85.6 & $(81.9-88.6)$ \\
\hline$>65$, years & 44.1 & $(43.4-44.8)$ & 44.5 & $(43.8-45.2)$ & 14.4 & $(11.4-18.1)$ \\
\hline \multicolumn{7}{|l|}{ Gender } \\
\hline Male & 46.6 & $(45.9-47.3)$ & 46.2 & $(45.5-47.0)$ & 76.3 & $(69.9-81.7)$ \\
\hline Female & 53.4 & $(52.7-54.1)$ & 53.8 & $(53.0-54.5)$ & 23.7 & $(18.3-30.1)$ \\
\hline \multicolumn{7}{|l|}{ Race/ethnicity } \\
\hline White & 72.8 & $(72.0-73.5)$ & 73.0 & $(72.2-73.7)$ & 56.9 & $(49.6-63.9)$ \\
\hline Black & 10.4 & $(9.9-10.9)$ & 10.2 & $(9.7-10.7)$ & 25.0 & $(19.8-31.1)$ \\
\hline Hispanic & 10.5 & $(9.9-11.0)$ & 10.4 & $(9.9-11.0)$ & 11.8 & $(8.6-16.0)$ \\
\hline Asian/other & 6.4 & $(6.1-6.7)$ & 6.4 & $(6.0-6.7)$ & 6.3 & $(4.1-9.6)$ \\
\hline \multicolumn{7}{|l|}{ Education } \\
\hline Less than high school & 13.6 & $(13.0-14.1)$ & 13.4 & $(12.8-13.9)$ & 30.8 & $(25.6-36.5)$ \\
\hline High school diploma & 26.7 & $(26.1-27.3)$ & 26.6 & $(26.0-27.2)$ & 36.1 & $(31.2-41.2)$ \\
\hline Some college & 27.9 & $(27.3-28.6)$ & 28.0 & $(27.3-28.6)$ & 24.5 & $(19.8-30.0)$ \\
\hline College degree & 31.8 & $(31.0-32.6)$ & 32.1 & $(31.2-32.9)$ & 8.6 & $(6.3-11.7)$ \\
\hline \multicolumn{7}{|l|}{ Annual family income } \\
\hline$<\$ 20,000$ & 15.6 & $(15.0-16.1)$ & 15.2 & $(14.7-15.8)$ & 44.0 & $(36.9-51.3)$ \\
\hline$\$ 20,000-\$ 49,999$ & 30.0 & $(29.4-30.6)$ & 30.0 & $(29.4-30.6)$ & 29.5 & $(24.9-34.5)$ \\
\hline$\$ 50,000-\$ 74,999$ & 16.4 & $(15.9-16.9)$ & 16.4 & $(15.9-16.9)$ & 14.4 & $(10.0-20.4)$ \\
\hline$>\$ 75,000$ & 38.0 & $(37.2-38.9)$ & 38.3 & $(37.5-39.2)$ & 12.1 & $(9.0-16.0)$ \\
\hline \multicolumn{7}{|l|}{ Relationship status } \\
\hline Not married & 38.2 & $(37.5-38.9)$ & 37.9 & $(37.2-38.6)$ & 64.9 & $(59.5-69.9)$ \\
\hline Married & 61.8 & $(61.1-62.5)$ & 62.1 & $(61.4-62.8)$ & 35.1 & $(30.1-40.5)$ \\
\hline \multicolumn{7}{|l|}{ Health insurance status } \\
\hline No health insurance & 4.5 & $(4.3-4.8)$ & 4.4 & $(4.1-4.7)$ & 17.1 & $(13.5-21.4)$ \\
\hline
\end{tabular}

CI, confidence interval. All $\chi^{2}$ ps $<0.001$

As is shown in Table 2, justice-involved adults age $\geq 50$ reported a higher percentage of mental illness (20.8\% vs. $6.2 \%$; $p<0.001)$, COPD (12.1\% vs. $7.4 \%, p<0.001)$, cirrhosis $(2.1 \%$ vs. $0.5 \%, p<0.001)$, and hepatitis B or C $(9.0 \%$ vs. $2.0 \%, p<0.001)$, but were less likely to report high blood pressure $(23.1 \%$ vs $33.7 \%, p<0.002)$ compared with adults not justice-involved. There was no statistically significant difference between the two groups regarding medical multimorbidity. In terms of SUDs, justice-involved adults reported a higher percentage across all substances examined, and for having any SUD (34.7\% vs. 3.7\%, $p<0.001)$. In addition, justice-involved adults age $\geq 50$ were more likely to report all combinations of co-occurring outcomes (any SUD, mental illness, and medical multimorbidity) including having all three simultaneously $(3.3 \%$ vs. $0.3 \%, p<0.001)$.

In our adjusted models shown in Table 3 , with all else being equal, among adults age $\geq 50$, justice-involved adults were at increased odds for mental illness (adjusted odds ratio [aOR] = $3.04,95 \%$ CI $=2.09-4.41$ ), past-year SUD for each substance examined, and for any SUD $(\mathrm{aOR}=8.10,95 \% \mathrm{CI}=6.12-$ 10.73). In terms of co-occurring conditions, justice-involved adults were at increased odds of all combinations of the outcomes, including all three simultaneously $(\mathrm{aOR}=8.56$, 95\% CI $=4.10-17.86$ ). In sensitivity analysis (Supplemental Table 1), we found that adults arrested or booked had higher odds of mental illness, any SUD, and all combinations of the outcomes compared with adults who were on probation or parole. We also found that being on probation was not a significant correlate of mental illness when utilizing the Bonferroni correction $(p=0.01)$ and that those on probation or parole did not have a significantly increased odds of cooccurring medical multimorbidity, mental illness, or for all three outcomes concurrently while considering the Bonferroni correction ( $p=0.03$ for parole and $p=0.004$ for probation). Thus, recent arrest appeared to somewhat drive significant associations with respect to mental illness. Patterns of medical multimorbidity and SUD for alcohol, cocaine, heroin, prescription opioids, and all opioids remained similar across the 3 subgroups.

\section{DISCUSSION}

This study of adults age $\geq 50$ living in the community with involvement in the criminal justice system found a high prevalence of SUDs and mental illness and is consistent with past research. $^{7,} 13$ While most SUD interventions for criminal justice populations focus on opioids and alcohol, ${ }^{24,25}$ our study adds a more granular examination of SUD patterns and reveals a high prevalence of alcohol, opioid, cocaine, and methamphetamine use disorders. As older adults who use stimulants may be at particularly high risk for death, ${ }^{26}$ these findings should be considered in harm reduction 
Table 2 Chronic Disease, Mental Illness, and Substance Use Disorder Prevalence among Middle-Aged and Older Adults According to JusticeInvolved Status in the USA, 2015-2018

\begin{tabular}{|c|c|c|c|c|c|}
\hline \multirow{2}{*}{$\begin{array}{l}\text { Characteristic } \\
\text { Mental illness (past-year) }\end{array}$} & \multicolumn{2}{|c|}{$\begin{array}{l}\text { Non-justice-involved } \\
\text { adults age } 50 \text { and older } \\
(n=34,437), \text { weighted } \\
\%(95 \% \text { CI })\end{array}$} & \multicolumn{2}{|c|}{$\begin{array}{l}\text { Justice-involved adults } \\
\text { age } 50 \text { and older }(n= \\
461) \text {, weighted } \%(95 \% \\
\text { CI })\end{array}$} & \multirow[t]{2}{*}{$\chi^{2} p$ value } \\
\hline & & & & & \\
\hline Serious or moderate mental illness & 6.2 & $(5.9-6.5)$ & 20.8 & $(15.9-26.8)$ & $<0.001$ \\
\hline \multicolumn{6}{|l|}{ Chronic disease (lifetime) } \\
\hline Asthma & 8.0 & $(7.7-8.4)$ & 8.1 & $(5.1-12.8)$ & 0.95 \\
\hline Bronchitis/COPD & 7.4 & $(7.0-7.7)$ & 12.1 & $(8.3-17.3)$ & 0.01 \\
\hline Cancer & 11.8 & $(11.5-12.2)$ & 3.3 & $(2.0-5.6)$ & $<0.001$ \\
\hline Cirrhosis & 0.5 & $(0.5-0.6)$ & 2.1 & $(1.0-4.1)$ & $<0.001$ \\
\hline Diabetes & 17.8 & $(17.3-18.3)$ & 21.6 & $(16.9-27.2)$ & 0.13 \\
\hline Heart condition & 18.7 & $(18.2-19.3)$ & 15.1 & $(11.1-20.2)$ & 0.15 \\
\hline Hepatitis B/C & 2.0 & $(1.9-2.2)$ & 9.0 & $(5.7-13.9)$ & $<0.001$ \\
\hline High blood pressure & 33.7 & $(33.0-34.3)$ & 23.1 & $(17.8-29.4)$ & 0.002 \\
\hline HIV/AIDS & 0.2 & $(0.2-0.3)$ & $*$ & $*$ & $*$ \\
\hline Kidney disease & 3.4 & $(3.2-3.7)$ & 3.2 & $(1.6-6.3)$ & 0.84 \\
\hline Medical multimorbidity ${ }^{\dagger}$ & 26.2 & $(25.6-26.7)$ & 23.9 & $(18.9-29.7)$ & 0.41 \\
\hline \multicolumn{6}{|l|}{ Substance use disorder (past-year) } \\
\hline Alcohol use disorder & 3.1 & $(2.8-3.3)$ & 25.6 & $(21.1-30.7)$ & $<0.001$ \\
\hline Cannabis use disorder & 0.3 & $(0.2-0.4)$ & 2.9 & $(1.5-5.5)$ & $<0.001$ \\
\hline Cocaine use disorder & 0.1 & $(0.1-0.2)$ & 5.9 & $(3.5-9.8)$ & $<0.001$ \\
\hline Heroin use disorder & 0.1 & $(0.0-0.1)$ & 2.7 & $(1.1-6.2)$ & $<0.001$ \\
\hline Methamphetamine use disorder & 0.1 & $(0.1-0.1)$ & 5.9 & $(3.5-9.8)$ & $<0.001$ \\
\hline Prescription opioid use disorder & 0.4 & $(0.3-0.4)$ & 6.0 & $(3.7-9.8)$ & $<0.001$ \\
\hline Prescription stimulant use disorder & 0.1 & $(0.0-0.1)$ & 0.7 & $(0.3-2.0)$ & $<0.001$ \\
\hline Tranquilizer/sedative use disorder & 0.1 & $(0.1-0.2)$ & 1.6 & $(0.7-3.6)$ & $<0.001$ \\
\hline Opioid use disorder (heroin or prescription opioid) & 0.4 & $(0.3-0.5)$ & 7.5 & $(4.8-11.5)$ & $<0.001$ \\
\hline Any substance use disorder (drug or alcohol use disorder) & 3.7 & $(3.5-4.0)$ & 34.7 & $(29.0-41.0)$ & $<0.001$ \\
\hline \multicolumn{6}{|l|}{ Co-occurring } \\
\hline Any SUD and mental illness & 0.8 & $(0.6-0.9)$ & 10.7 & $(8.0-14.2)$ & $<0.001$ \\
\hline Medical multimorbidity and mental illness & 2.6 & $(2.4-2.8)$ & 7.9 & $(5.1-11.8)$ & $<0.001$ \\
\hline Any SUD and medical multimorbidity & 0.9 & $(0.8-1.1)$ & 6.7 & $(4.5-10.0)$ & $<0.001$ \\
\hline Any SUD, medical multimorbidity, and mental illness & 0.3 & $(0.2-0.3)$ & 3.3 & $(1.8-6.0)$ & $<0.001$ \\
\hline
\end{tabular}

CI, confidence interval; SUD, substance use disorder; COPD, chronic obstructive pulmonary disease *Censored for $N<5$

${ }^{\dagger} 2$ or more of the above chronic diseases

interventions targeting this population. While middle-aged and older adults with justice involvement have high rates of opioid use disorder, only a small percentage of justiceinvolved adults receive evidence-based medications (e.g., methadone or buprenorphine). ${ }^{27}$ Increasing the availability of medications for opioid use disorder for justice-involved adults, such as low-threshold buprenorphine programs, ${ }^{28}$ especially for older adults with chronic medical disease is critical to reduce the risk of health-related harms and overdose. ${ }^{29}$

While we found a higher prevalence of cirrhosis, hepatitis, and COPD, consistent with prior studies of incarcerated adults, ${ }^{2,4}$ we did not identify a higher prevalence of medical multimorbidity. This may be due to differences in the definition of medical multimorbidity from other studies. ${ }^{8}$ In addition, we found a lower percentage of hypertension among justice-involved adults and no significant difference in heart disease, which contrasts with the literature of higher rates of cardiovascular disease and hypertension among recently incarcerated adults. ${ }^{14,}{ }^{30}$ This could be because this population may have more limited access to healthcare and therefore have fewer opportunities to receive a medical diagnosis. Further- more, we used national data of justice-involved adults who are living in the community, which may differ from other studies that have a heterogeneity of justice-involved populations. ${ }^{31}$ Despite similar rates of medical multimorbidity in justice- and non-justice-involved middle-aged and older adults, we found justice-involved adults age $\geq 50$ still had higher odds of having two or more co-occurring chronic conditions (including medical multimorbidity with mental illness and medical multimorbidity with SUD) compared with those not justiceinvolved. In particular, our sensitivity analysis showed that those who were arrested or booked had higher odds of having mental illness and experiencing co-occurring conditions relative to those on probation or parole. Thus, recent arrestees may represent a particularly high-risk group within middle-aged and older justice-involved adults that has implications for targeted interventions.

Mental illness and SUDs themselves are chronic diseases and therefore coupled with chronic medical diseases can represent a compound multimorbidity. The intersection of substance use, mental illness, and medical multimorbidity is complex and such high levels of multimorbidity among justice- 
Table 3 Multivariable Models Examining Justice Involvement as a Risk Factor for Chronic Disease, Mental Illness, and Substance Use Disorder among Middle-Aged and Older Adults in the USA, 2015-2018

Separate outcome variables

Justice-involved adults vs. non-justice-involved adults (independent variable).

Adjusted odds ratio, $95 \% \mathrm{CI}$

\section{Mental illness (past-year)}

Serious or moderate mental illness

3.04

$(2.09-4.41)$

Chronic disease (lifetime)

Medical multimorbidity ${ }^{\dagger}$

Substance use disorder (past-year)

Alcohol use disorder

Cannabis use disorder

Cocaine use disorder

Heroin use disorder

Methamphetamine use disorder

Prescription opioid use disorder

Prescription stimulant use disorder

1.15

$(0.85-1.56)$

Tranquilizer/sedative use disorder

Opioid use disorder (heroin or prescription opioid)

Any substance use disorder (drug or alcohol use disorder)

6.87 *

$3.49^{*}$

$11.21^{t}$

$16.65^{+}$

$21.85^{+}$

$7.73^{*}$

5.81

4.77

$8.31^{*}$

Co-occurring

Any SUD and mental illness

Medical multimorbidity and mental illness

Any SUD and medical multimorbidity

Any SUD, medical multimorbidity, and mental illness

$8.10^{*}$

$(5.18-9.12)$

$(1.65-7.36)$

$(5.09-24.68)$

$(5.70-48.61)$

(9.34-51.10)

$(4.39-13.63)$

$(1.87-17.99)$

(1.69-13.50)

$(4.89-14.14)$

$(6.12-10.73)$

7.82

2.59

(5.16-11.85)

$(1.53-4.38)$

$(3.74-9.85)$

$6.07^{*}$
$8.56^{*}$

$(4.10-17.86)$

CI, confidence interval; SUD, substance use disorder; COPD, chronic obstructive pulmonary disease

*Adjusted for age, gender, racelethnicity, marital status, education, income, and by whether participants had health insurance

$\dagger 2$ or more of the following chronic diseases: asthma, bronchitis/COPD, cancer, cirrhosis, diabetes, hepatitis B/C, heart condition, high blood pressure, HIV/AIDS, and kidney disease

tWe utilized a Bonferroni correction statistical correction and consider these variables significant at a $p<0.003$

involved middle-aged and older adults place this population at risk for poor outcomes. Interventions for this population must consider the interplay between each condition and how it contributes to overall multimorbidity to reduce harms and improve the management of chronic diseases. Several interventions have been developed or proposed to address either mental illness, SUD, or chronic medical diseases in this population, especially for those transitioning back to the community. ${ }^{24,}{ }^{25,}{ }^{32-34}$ Our results highlight the need to address these problems simultaneously. Existing multimorbidity models of geriatric-based care are best suited to accomplish this but must incorporate treatment for SUD and mental illness with traditional models that address medical multimorbidity, functional health, and geriatric conditions. The ability to integrate geriatric-based care with addiction medicine ${ }^{29}$ will be critical given the high prevalence of SUDs in this population.

Our study has limitations in that information is self-reported and therefore susceptible to limited recall and social desirability bias. Multiple testing could be a limitation, but test results ( $p$ s < 0.001) remained significant in light of a Bonferroni correction (alpha $=0.003$ ). In addition, our study is limited to community-living, justice-involved adults age 50 and older and not representative of adults currently incarcerated or subpopulations of justice-involved adults such as homeless individuals who do not use shelters or adults living in institutional group quarters. Also, this paper focused on any criminal justice involvement. Sensitivity tests found that many associations appear driven by recent arrestees, but we must keep in mind that only a small percentage $(<1 \%)$ of participants were on probation or parole and this could have limited our tests. Finally, NSDUH does not include a diagnostic interview. Responses to survey questions related to mental illness and SUD are used to determine proxy diagnosis and not a direct diagnosis. However, these proxy diagnoses in NSDUH are used extensively in the literature. ${ }^{7,16-21}$

Despite these limitations, this study using nationally representative data finds that middle-aged and older justiceinvolved adults living in the community are at increased risk for co-occurring morbidity from medical multimorbidity, mental illness, and SUDs. As most research focused on justice-involved populations examine SUDs and psychiatric illness among younger adults, our study adds to the literature by focusing on middle-aged and older adults who not only also experience high rates of SUD and mental illness but also are at higher risk for chronic medical diseases. Finally, this study indicates the need to consider how co-occurring conditions contribute to poor health outcomes to deliver patientcentered care to an often-overlooked medically vulnerable population.

Corresponding Author: Benjamin H. Han, MD; Department of Medicine, Division of Geriatrics and Gerontology, University of 
California San Diego, ?9500 Gilman Drive, Mail Code 0665, San Diego, CA 92093, USA (e-mail: b2han@health.ucsd.edu).

Funding This research is funded by grants from the National Institute of Health: Drs. Joseph Palamar and Benjamin Han were funded by grants from the National Institute on Drug Abuse: K01DA038800 (Palamar), R01DA044207 (Palamar) and K23DA043651 (Han). Dr. Williams was funded by grants from the National Institute on Aging: R24AG065175 and P30AG044281. The content is solely the responsibility of the authors and does not necessarily represent the official views of the National Institutes of Health.

\section{Compliance with Ethical Standards:}

Conflict of Interest: The authors declare no conflict of interest.

\section{REFERENCES}

1. Pew Charitable Trusts. Aging Prison Populations Drive Up Costs. http:// pewtrusts.org/en/research-and-analysis/articles/2018/02/20/agingprison-populations-drive-up-costs. Accessed April 15, 2020.

2. Baillargeon J, Soloway RD, Paar DP, et al. End-stage liver disease in a state prison population. Ann Epidemiol. 2007;17:808-813.

3. Spaulding AC, Seals RM, Page MJ, Brzozowski AK, Rhodes W, Hammett TM. HIV/AIDS among inmates of and releasees from US correctional facilities, 2006: declining share of epidemic but persistent public health opportunity. PLoS One. 2009;4(11):e7558. doi:https://doi.org/10.1371/ journal.pone. 0007558

4. U.S. Department of Justice. Medical Problems of State and Federal Prisoners and Jail Inmates, 2011-12. https://www.bjs.gov/content/ pub/pdf/mpsfpji1112.pdf. Accessed April 15, 2020.

5. Primeau A, Bowers TG, Harrison MA, Xu, X. Deinstitutionalization of the mentally ill: evidence for trans-institutionalization from psychiatric hospitals to penal institutions. Compr Psychol. 2013;2:2. https://doi. org/10.2466/16.02.13.CP.2.2

6. U.S. Department of Justice. Drug Use and Dependence, State and Federal Prisoners, 2004. https://www.bjs.gov/content/pub/pdf/ dudsfp04.pdf. Accessed April 15, 2020.

7. Bryson WC, Cotton BP, Brooks JM. Mental Health, Substance Use, and Socioeconomic Needs of Older Persons Paroled or Placed on Probation. Psychiatr Serv. 2017;68(6):640-641.

8. Greene M, Ahalt C, Stijacic-Cenzer I, Metzger L, Williams B. Older adults in jail: high rates and early onset of geriatric conditions. Health Justice. 2018;6(1):3.

9. Abram KM, Teplin LA. Co-occurring disorders among mentally ill jail detainees: implications for public policy. Am Psychol. 1991;46(10):10361045.

10. Semenza DC, Grosholz JM. Mental and physical health in prison: how cooccurring conditions influence inmate misconduct. Health Justice. 2019;7(1):1.

11. Boyd CM, Fortin M. Future of multimorbidity research: how should understanding of multimorbidity inform health system design? Public Health Rev. 2010;32:451-474.

12. Lehnert T., Heider D., Leicht H. Review: health care utilization and costs of elderly persons with multiple chronic conditions. Med. Care Res. Rev. 2011;68:387-420.

13. Williams BA, Goodwin JS, Baillargeon J, Ahalt C, Walter LC. Addressing the aging crisis in U.S. criminal justice health care. J Am Geriatr Soc. 2012;60(6):1150-1156.

14. Binswanger IA, Stern MF, Deyo RA, et al. Release from prison-a high risk of death for former inmates. N Engl J Med. 2007; 356:157-165.
15. Zlodre J, Fazel S. All-cause and external mortality in released prisoners: systematic review and meta-analysis. Am $\mathrm{J}$ Public Health. 2012;102(12):e67-e75.

16. Center for Behavioral Health Statistics and Quality. Results from the 2018 National Survey on Drug Use and Health: Detailed Tables. Rockville: Substance Abuse and Mental Health Services Administration; 2019.

17. Farrell CM, Gottlieb A. The Effect of Health Insurance on Health Care Utilization in the Justice-Involved Population: United States, 2014-2016. Am J Public Health. 2020;110(S1):S78-S84. doi:https://doi.org/10. 2105/AJPH.2019.305399.

18. Gutierrez CM, Pettit B. Employment and Health Among Recently Incarcerated Men Before and After the Affordable Care Act (2009-2017). Am J Public Health. 2020;110(S1):S123-S129. doi:https://doi.org/10. 2105/AJPH.2019.305419

19. Substance Abuse and Mental Health Services Administration. National Survey on Drug Use and Health: Alternative Statistical Models to Predict Mental Illness. Rockville: Substance Abuse and Mental Health Services Administration (US); 2015. https://www.ncbi.nlm.nih.gov/books/ NBK531554. Accessed March 31, 2020.

20. Han BH, Ko R, Palamar JJ. Substance Use by Adults with Medical Multimorbidity in the United States, 2015-2016. J Gen Intern Med. 2019;34, 1394-1396.

21. Mckee MM, Meade MA, Zazove P, Stewart HJ, Jannausch ML, Ilgen MA The Relationship Between Hearing Loss and Substance Use Disorders Among Adults in the U.S. Am J Prev Med. 2019;56(4):586-590.

22. StataCorp. Stata Statistical Software: Release 13. College Station: StataCorp LP2013.

23. Heeringa SG, West BT, Berglund PA. Applied survey data analysis. London: Chapman and Hall: CRC Press; 2010.

24. Belenko S, Hiller M, Hamilton L. Treating substance use disorders in the criminal justice system. Curr Psychiatry Rep. 2013;15(11):414.

25. Lee JD, Friedmann PD, Kinlock TW, et al. Extended-Release Naltrexone to Prevent Opioid Relapse in Criminal Justice Offenders. N Engl J Med. 2016;374(13): 1232-1242.

26. Han BH, Tuazon E, Kunins HV, Mantha S, Paone D. Unintentional drus overdose deaths involving cocaine among middle-aged and older adults in New York City. Drug Alcohol Depend. 2019; 198: 121-125.

27. Krawczyk N, Picher CE, Feder KA, Saloner B. Only One In Twenty Justice-Referred Adults In Specialty Treatment For Opioid Use Receive Methadone Or Buprenorphine. Health Aff (Millwood). 2017;36(12):20462053. doi:https://doi.org/10.1377/hlthaff.2017.0890

28. Krawczyk N, Buresh M, Gordon MS, Blue TR, Fingerhood MI, Agus D. Expanding low-threshold buprenorphine to justice-involved individuals through mobile treatment: Addressing a critical care gap. J Subst Abuse Treat. 2019;103:1-8. doi:https://doi.org/10.1016/j.jsat.2019.05.002

29. Han BH. Aging, multimorbidity, and substance use disorders: The growing case for integrating the principles of geriatric care and harm reduction. Int J Drug Policy. 2018;58:135-136.

30. Howell BA, Long JB, Edelman EJ, et al. Incarceration History and Uncontrolled Blood Pressure in a Multi-Site Cohort. J Gen Intern Med. 2016;31(12):1496-1502. doi:https://doi.org/10.1007/s11606-016$3857-1$

31. Fazel S, Danesh J. Serious mental disorder in 23000 prisoners: a systematic review of 62 surveys. Lancet. 2002;359(9306):545-550. doi:https://doi.org/10.1016/S0140-6736(02)07740-1

32. Bryson WC, Cotton BP, Barry LC, et al. Mental health treatment among older adults with mental illness on parole or probation. Health Justice. 2019;7(1):4

33. O'Connell DJ, Visher CA, Becker P. Linking individuals on probation to health care: a pilot randomized trial. Health Justice. 2020;8(1):8. doi:https://doi.org/10.1186/s40352-020-00110-w

34. Wang EA, Hong CS, Shavit S, Sanders R, Kessell E, Kushel MB. Engaging Individuals Recently Released From Prison Into Primary Care: A Randomized Trial. Am J Public Health. 2012;102(9):e22-e29. doi:https://doi. org/10.2105/AJPH.2012.300894

Publisher's Note: Springer Nature remains neutral with regard to jurisdictional claims in published maps and institutional affiliations. 